\title{
Anti-Metatype Antibody Screening, Sandwich Immunoassay Development, and Structural Insights for $\beta$-Lactams Based on Penicillin Binding Protein
}

\author{
Yuchen Bai, Leina Dou, Weilin Wu, Zhimin Lu, Jiaqian Kou, Jianzhong Shen, Kai Wen * and Zhanhui Wang \\ College of Veterinary Medicine, China Agricultural University, Beijing Key Laboratory of Detection Technology \\ for Animal Derived Food Safety, Beijing Laboratory for Food Quality and Safety, Beijing 100193, China; \\ BS20193050465@cau.edu.cn (Y.B.); echodou17@163.com (L.D.); 2016305010312@cau.edu.cn (W.W.); \\ S20203050782@cau.edu.cn (Z.L.); kjq2182266753@163.com (J.K.); sjz@cau.edu.cn (J.S.); \\ wangzhanhui@cau.edu.cn (Z.W.) \\ * Correspondence: wenkai@cau.edu.cn; Tel.: +86-10-273-4565
}

check for updates

Citation: Bai, Y.; Dou, L.; Wu, W.; Lu, Z.; Kou, J.; Shen, J.; Wen, K.; Wang, Z. Anti-Metatype Antibody Screening,

Sandwich Immunoassay

Development, and Structural Insights for $\beta$-Lactams Based on Penicillin Binding Protein. Molecules 2021, 26, 5569. https://doi.org/10.3390/ molecules26185569

Academic Editor: Martin Danaher

Received: 5 August 2021

Accepted: 8 September 2021

Published: 13 September 2021

Publisher's Note: MDPI stays neutral with regard to jurisdictional claims in published maps and institutional affiliations.

Copyright: (c) 2021 by the authors. Licensee MDPI, Basel, Switzerland. This article is an open access article distributed under the terms and conditions of the Creative Commons Attribution (CC BY) license (https:// creativecommons.org/licenses/by/ $4.0 /)$.
Abstract: Theoretically, sandwich immunoassay is more sensitive and has a wider working range than that of competitive format. However, it has been thought that small molecules cannot be detected by the sandwich format due to their limited size. In the present study, we proposed a novel strategy for achieving sandwich immunoassay of $\beta$-lactams with low molecular weights. Firstly, five $\beta$-lactam antibiotics were selected to bind with penicillin binding protein (PBP) $2 x^{*}$ to form complexes. Then, monoclonal and polyclonal antibodies against PBP $2 x^{*}-\beta$-lactams complexes were produced by animal immunization. Subsequently, the optimal pairing antibodies were utilized to establish sandwich immunoassay for detection of 18 PBP $2 x^{*}-\beta$-lactam complexes. Among them, ceftriaxone could be detected at as low as $1.65 \mathrm{ng} / \mathrm{mL}$ with working range of $1-1000 \mathrm{ng} / \mathrm{mL}$ in milk. To reveal the detection mechanism, computational chemistry and molecular recognition study were carried out. The results showed that $\beta$-lactams with a large size and complex structures maybe conducive to induce conformational changes of $\mathrm{PBP} 2 \mathrm{x}^{*}$, and then exhibit greater possibility of being detected by sandwich immunoassay after combination with PBP2 $x^{*}$. This study provides insights for subsequent investigations of anti-metatype antibody screening and sandwich immunoassay establishment for small-molecule detection.

Keywords: sandwich immunoassay; $\beta$-lactams; PBP2x; anti-metatype antibody; computational chemistry; molecular recognition

\section{Introduction}

Immunoassays are nowadays being employed for rapid contaminant analysis in clinical, environmental, and food samples [1,2]. The formats of immunoassay are roughly categorized as either non-competitive or competitive. The competitive immunoassay is based on the competition between protein-labeled analyte and the analyte for limited antibody amount. Conversely, the non-competitive immunoassay, generally known as the sandwich format, involves the use of two antibodies (one for capturing analyte and another labeled by an enzyme for detection), which can be added in excess [3,4]. Typically, the sandwich immunoassay yields considerable benefits in sensitivity, working range, and specificity compared to the competitive format. However, small molecules with molecular weights below $1000 \mathrm{Da}$ are generally detected based on the competitive format due to the steric hindrance [5]. Many attempts have been made to establish non-competitive assays for small molecules, including the use of anti-idiotypic antibodies, anti-metatype antibodies, and recombinant $\mathrm{VH}$ and $\mathrm{VL}$ to form an open sandwich immunoassay [6-10]. Among these, the use of anti-metatype antibodies closely resembles the sandwich immunoassay. The anti-metatype antibodies are developed from animals immunized with the receptorligand complex, which may recognize parts of the structure of both the ligand and receptor 
at the same time or the conformational change on the receptor induced by binding, but exhibit very low or no affinity for the receptor or the ligand alone [5]. The success of the development of anti-metatype antibodies depends on the stability of the receptor-ligand complex [9].

$\beta$-lactams refer to a class of antibiotics with a $\beta$-lactam ring in their chemical structure, which destroys the cell wall of bacteria by inhibiting cell wall mucopeptide synthetase, resulting in the expansion and lysis of bacteria. According to the structural characteristics, $\beta$-lactams can be classified into two main types, including penicillins and cephalosporins, which are essential antibacterial chemotherapy drugs and are widely used in the treatment of bacterial infections because of their broad spectrum of activity, clinical effectiveness, and safety profile (Figure 1) [11,12]. Even if they are reputed to be products with low toxicity, the overuse and misuse of $\beta$-lactams may lead to residues in food and can contribute to public health problems such as allergic reactions, dysbiosis of the gut flora, and even carcinogenicity. The antibiotic-resistant bacteria that are pathogenic to humans may also occur, thereby presenting a significant challenge in infection treatment and control. Furthermore, $\beta$-lactam antibiotic residues in milk also interfere in fermentation processes used in cultured dairy products; e.g., yogurt. To improve food quality and ensure human health safety, the Commission Regulation (EU) No. 37/2010 has established maximum residue limits (MRL) of $\beta$-lactams in dairy products such as muscle, liver, kidney, fat, milk, or eggs [13].<smiles>[R]C(=O)N[C@@H]1C(=O)N2[C@@H]1SC(C)(C)[C@H]2C(=O)O</smiles>

Penicillin<smiles>[R3]C(=O)N[C@@H]1C(=O)N2C(C(=O)O)=C([R4])CS[C@H]12</smiles>

Cephalosporin

Figure 1. The structures of penicillin and cephalosporin. The $\beta$-lactam scaffolds are shown in black, and the different side chain structures of $\beta$-lactam are shown as $R$ in red.

Thus, various methods have been developed to determine the $\beta$-lactam residues that can be classified into three main categories: microbial inhibition, chromatographic techniques, and immunoassays [14-18]. Of these, the immunoassays are portable and costeffective with high sensitivity and selectivity, and are capable of screening large numbers of samples [1,2]. However, it is quite difficult to produce antibodies that could achieve simultaneous identification of $\beta$-lactams due to the diversity of the molecular structure of these drugs $[19,20]$. Recently, research studies on $\beta$-lactam detection based on their receptors, termed as penicillin binding proteins (PBPs), which can recognize a variety $\beta$-lactams simultaneously, have been increasingly applied in $\beta$-lactam screening [21]. Some assays for the multi-residue analysis of $\beta$-lactams based on PBPs have been reported [22-24]. Noticeably, these methods are based on the competitive format, which is designed as reagent limited, always leading to poor sensitivity and with a narrow analytical range compared to non-competitive format.

In our previous study, we successfully expressed a recombinant PBP named PBP2 $x^{*}$, and a multi-residue competitive assay for detecting $\beta$-lactams was developed [24]. Earlier studies demonstrated that the spatial conformation of PBP2 $x^{*}$ would change after the combination with $\beta$-lactams $[25,26]$. Therefore, in the present study, we explored the screening of anti-metatype antibodies for recognizing the complexes formed by PBP $2 x^{*}$ and $\beta$-lactams, as well as the development of a sandwich immunoassay for $\beta$-lactams. Firstly, five $\beta$-lactams with high affinity to PBP2 $x^{*}$ were selected to bind with PBP2 $x^{*}$ to serve as immunogens. Subsequently, the monoclonal antibodies $(\mathrm{mAb})$ and polyclonal antibodies $(\mathrm{pAb})$ that could identify the PBP $2 \mathrm{x}^{*}-$ drug complexes were prepared, and the best pairing 
antibodies used as capture and detection antibodies in sandwich immunoassay were obtained, respectively. Eighteen $\beta$-lactams were combined with PBP $2 x^{*}$ and then evaluated by the sandwich assay, and a real sandwich immunoassay for ceftriaxone (CTRX) detection with high sensitivity and wide detection range was successfully established (Figure 2). Furthermore, the insights into relationship between the structure of $\beta$-lactams and the conformational change of the PBP $2 x^{*}$ were provided based on computational chemistry and molecular recognition study. To the authors' knowledge, this work presents the first attempt to prepare anti-metatype antibodies for $\beta$-lactams based on PBP. More importantly, the study provides valuable references for further antibody screening and the development of more broad-spectrum non-competitive immunoassay for $\beta$-lactam detection.

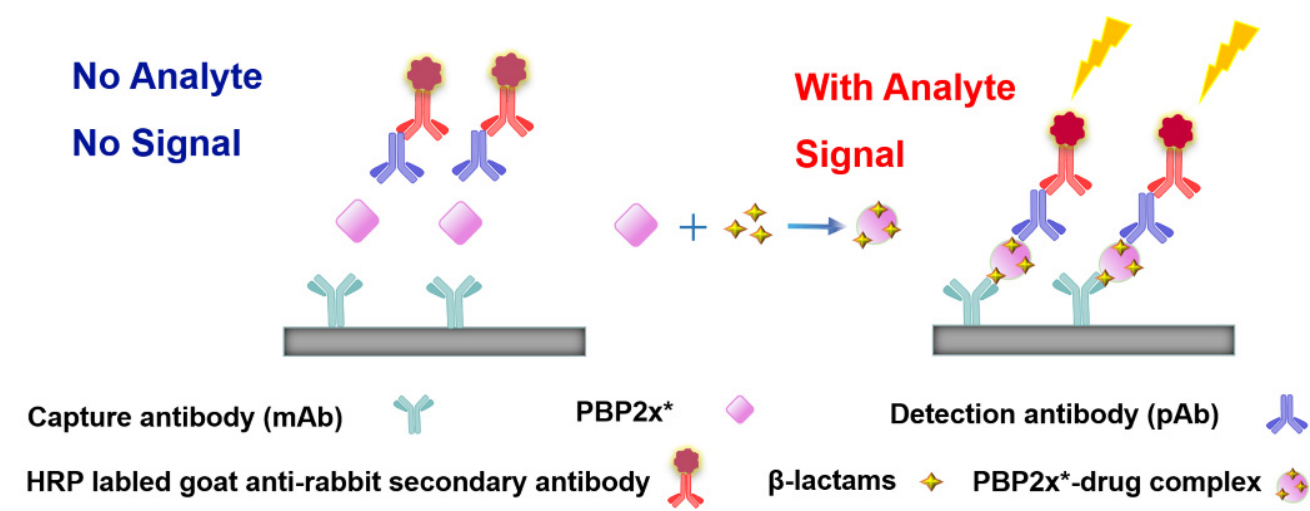

Figure 2. Schematic representation of sandwich immunoassay for small-molecule detection based on $\mathrm{PBP} 2 \mathrm{x}^{*}$

\section{Results and Discussion}

\subsection{Subsection}

2.1.1. Determination of the Binding Ability of $\beta$-Lactams to PBP2x*

The anti-metatype antibodies that recognize the complex formed by the receptor and ligand was developed by immunization [5]. The success of the immunization depends on the stability of the receptor-drug complex [9]. In the present study, we hypothesized that the complex formed by PBP $2 x^{*}$ and $\beta$-lactams with high affinity to PBP $2 x^{*}$ would achieve higher stability, because more non-covalent bonds typically tend to form between the two. In addition, the conformational change of PBP $2 x^{*}$ induced by the combination of the $\beta$-lactams with high affinity may be greater due to the existence of more interaction forces, which stimulate the PBP $2 x^{*}$ to some extent [27]. Therefore, a direct competitive ELISA was carried out to determine the affinity of $18 \beta$-lactams to PBP2x*. As shown in Table 1, among the eight penicillins, PNG, AMP, AMX, AZL, and PIPC exhibited high affinity to PBP2x*, while OXA, CLX, and DCX showed relatively poor affinity. In the cephalosporin group, CPZ, CFN, CFZ, and CFM performed poorly: affinities with $\mathrm{IC}_{50}$ were greater than $10 \mathrm{ng} / \mathrm{mL}$, which was almost 2-50-fold that of other drugs such as CTRX, CTX, and KF. (Table 2). Therefore, for the preparation of anti-metatype antibodies, five $\beta$-lactams (including PNG, AMP, AMX, CTX, and KF) with high affinity to PBP2x* were selected to form a complex with PBP2x*.

\subsubsection{Identification of Immunogens and Production of Anti-Metatype Antibodies}

The quality of the immunogen is crucial for the antibody response. In this study, which differed from previous works [7-9], we used a receptor-drug complex as the immunogen, rather than a complex formed by an antibody and a drug. The central difference between the two is that an antibody usually identifies a specific target drug, while a receptor can recognize a class of drugs. Thus, five $\beta$-lactams (including PNG, AMP, AMX, CTX, and KF) with high affinity to PBP $2 x^{*}$ were selected to form complexes with $\mathrm{PBP} 2 \mathrm{x}^{*}$, which were then used as immunogens to immunize mice or rabbits to obtain antibodies against themselves. To ensure that all sites of PBP $2 x^{*}$ were occupied by the drugs, the prepared complexes were 
identified by direct non-competitive ELISA. The results showed that there was almost no color development (OD values $<0.1$, Table S1) for five PBP2 $x^{*}$-drug complexes, indicating that the sites of PBP2 $x^{*}$ had been fully occupied by drugs, which could be used as qualified immunogens for subsequent immunization.

The antisera of rabbits and mice immunized with five immunogens were screened against their homologous PBP2 $x^{*}$-drug complexes using indirect non-competitive ELISA, and the separate PBP2x* was also coated as control. Relatively high dilution of all 11 rabbit antisera were observed and collected after the fourth injection due to the death of one rabbit injected with immunogen PBP2 $x^{*}-\mathrm{CTX}$. Among immunized mice, the antisera from PBP $2 x^{*}-\mathrm{AMP}$ yielded the highest titer, and thus was selected for cell fusion. After four subcloning processes using the limiting dilution method, a total of 31 hybridomas were obtained.

Table 1. The affinity of penicillins to PBP2 $x^{*}$.

Penicillins


Table 2. The affinity of cephalosporins to PBP2x*

\begin{tabular}{|c|c|c|c|}
\hline Cephalosporins & Structures of R1 & Structures of R2 & $\mathrm{IC}_{50}(\mathrm{ng} / \mathrm{mL})$ \\
\hline Cefatriaxone (CTRX) & & & 2.35 \\
\hline Ceftiofur (CFT) & & & 2.63 \\
\hline Cefotaxime (CTX) & & & 4.75 \\
\hline Cefapirin (CFAP) & & & 6.05 \\
\hline Cefepime (CFP) & & & 7.32 \\
\hline Cefalothin (KF) & & & 7.89 \\
\hline Cefalonium (CFN) & & & 15.30 \\
\hline Cefazolin (CFZ) & & & 24.36 \\
\hline Cefixime (CFM) & & & 29.33 \\
\hline Cefoperazone (CPZ) & & & 100.22 \\
\hline
\end{tabular}

\subsubsection{Screening of Antibody Pairs}

To screen the antibody pairs against the complex formed by PBP2x* and $\beta$-lactams, 11 pAbs and $31 \mathrm{mAbs}$ were carried for sandwich immunoassays experiments, further leading to 321 antibody combinations for $\beta$-lactams to be tested. To improve the screening efficiency, seven $\beta$-lactams (PNG, AMX, AMP, OXA, CLX, CTX, and KF) were first chosen as the standard. Among the tested antibodies, the mAb $4 \mathrm{H} 11$ and $\mathrm{pAb} \# 5$ derived from immunogen PBP2 $x^{*}-\mathrm{CTX}$ were selected as the capture and detection antibody, respectively, due to their better capacity to undergo sandwich immunoassays for OXA, CLX, and CTX. Thus, the selected pair of antibodies was employed to further evaluate the other $11 \beta$ lactams. As shown in Figure 3a, aside from OXA, CLX, and CTX, the signal-to-noise $(\mathrm{S} / \mathrm{N})$ values of AZL, DCX, CTRX, CFT, CTX, CFP, CFM, and CPZ at a concentration of $1000 \mathrm{ng} / \mathrm{mL}$ were also greater than 1.0, indicating a trend of being detected by sandwich 
immunoassay. Among these, the CTRX yielded the best detection performance, reaching a high S/N value of 2.84. Therefore, a rapid and highly sensitive sandwich immunoassay for detection of CTRX was established. Under the optimized experimental conditions, standard solutions were diluted in milk samples without any previous dilution or centrifugation at concentrations of $0.1,1,10,100$, and $1000 \mathrm{ng} / \mathrm{mL}$, and a standard curve of sandwich ELISA for CTRX detection was constructed with an LOD of $1.65 \mathrm{ng} / \mathrm{mL}$ and a working range of 1-1000 ng/mL (Figure 3b).

(a)

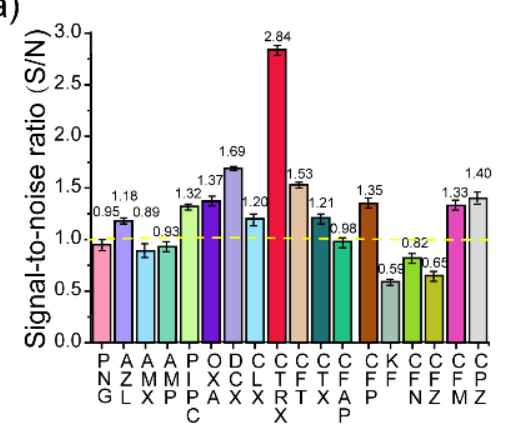

(b)

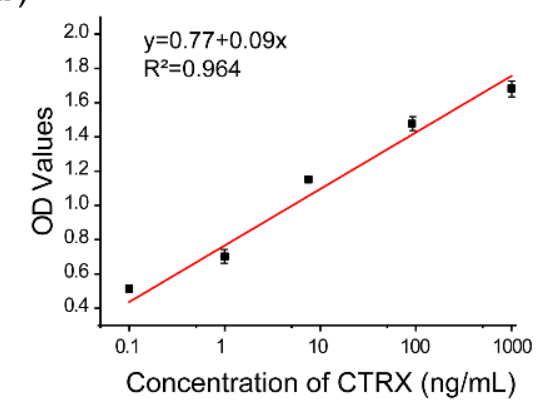

Figure 3. (a) The $\mathrm{S} / \mathrm{N}$ of the sandwich immunoassay for detection of $18 \beta$-lactams $(n=3) . \mathrm{S} / \mathrm{N}>1$ indicates positive detection by the sandwich immunoassay, while $\mathrm{S} / \mathrm{N} \leq 1$ indicates negative detection. (b) Standard curve of the sandwich immunoassay for CTRX detection $(n=3)$.

Theoretically, the anti-metatype antibodies recognize the receptor-ligand complex, but exhibit very low or no affinity for the receptor or the ligand alone. However, in the present study, the selected antibodies were observed to recognize the separate PBP2 $x^{*}$ to some extent, resulting in high background values of $0.3-0.5$. This may be related to the fact that the detection antibody used in the sandwich immunoassay was pAb, which contains antibodies that not only recognize the new epitopes created by the binding of PBP $2 x^{*}$ and $\beta$-lactams, but also other epitopes of separate PBP2 $x^{*}$. Therefore, the use of $\mathrm{pAb}$ should be avoided whenever possible in further related studies. In addition, when applied to the 18 $\beta$-lactams, the sandwich immunoassay did not always detect drugs that exhibited high affinity to PBP2 $x^{*}$. Of the five immunized $\beta$-lactams (including PNG, AMP, AMX, CTX, and KF), only CTX showed an upward trend $(\mathrm{S} / \mathrm{N}>1)$ in the sandwich immunoassay when the CTX concentration was increased, while the other four high-affinity drugs failed to lead to sandwich immunoassays $(\mathrm{S} / \mathrm{N}<1$ ) (Figure 3a). Conversely, the OXA, DCX, CLX, $\mathrm{CFM}$, and CPZ, which possessed poor affinity with PBP2 $x^{*}$, seemed to be better recognized after combination with PBP2 $x^{*}$ by sandwich immunoassay. The unexpected result drove us to further explore the binding mechanism between PBP2 $x^{*}$ and $\beta$-lactams.

\subsubsection{Research on the Binding Mechanism of PBP2x* and $\beta$-Lactams}

Initially, we assumed that the complexes consisting of high-affinity $\beta$-lactams and PBP2 $x^{*}$ were more stable, and the greater conformation changes of PBP2 $x^{*}$ might be induced, which was expected to obtain more effective anti-metatype antibodies and therefore more easily achieve sandwich immunoassay for $\beta$-lactam detection. However, the results were almost the opposite, and further exploration should be carried out. According to previous studies, the shape of the receptor binding pocket was originally influenced by the molecular structure and properties of the ligand, which in turn affected the subsequent production of the antibody against conformational change of receptor [28]. Therefore, on the basis of lowest energy conformations, we extracted physicochemical descriptors of 18 $\beta$-lactams including molecular volume/surface, $\log \mathrm{P}$, etc., by computational chemistry. As shown in Table S2, the $\beta$-lactams, such as DCX, PIPC, CPZ, CTRX, CFT, etc., which possessed lower energies, larger surface areas, and larger volumes, were observed to be more accessible to sandwich immunoassay. Therefore, the size and complexity of molecular 
structure may be a key factor affecting the conformational change of the receptor in the binding process.

To further explain the scientific base behind the new binding model we proposed, structural studies on $18 \beta$-lactams in complex with crystal structure of PBP2x (PDB code: $2 \mathrm{z} 2 \mathrm{~m}$ ) were conducted. As shown in Figures 4 and S1, in the group of penicillins, the parent nucleus structure (6-aminopenicillanic acid) of eight drugs was deeply inserted into the binding cavity surrounded by the main residues ASN397, SER337, THR550, GLU334 PHE450, TRP374, and TYP561, while the C6 side chain pointed outward. We speculated that during the binding process, the parent nucleus moiety of penicillins firstly bound to $\mathrm{PBP} 2 \mathrm{x}^{*}$, and in turn entered the binding cavity via the help of hydrogen bonding forces and hydrophobic forces, and the side chain moiety subsequently reached the cavity. In this context, despite that the interactions between the side chain moiety and the PBP $2 x^{*}$ were less than the parent nucleus moiety, it still had an important effect on the formation of the binding cavity openings (Figure S1). The side chain of AZL, PIPC, OXA, DCX, and CLX is a double-ring structure, which is more complex and more rigid than the single-ring structure of PNG, AMX, and AMP. Coincidentally, the drugs with a more complex side chain had a greater probability of being recognized by the antibody after binding to the receptor, as shown in Figure 3a. Among these, the benzo isoxazole structure of OXA, DCX, and CLX showed rotations of almost $90^{\circ}$ in the binding cavity, which indicated low fitness with PBP2 $x^{*}$, thus belonging to the low-affinity ligand. However, such deflections induced by rigid structure of drugs may easily cause structural changes of the receptor in the binding cavity, and thereby more likely to be identified by anti-metatype antibodies. Similar results were observed in the cephalosporin group: the cephalosporins with more complex structures in the $\mathrm{C} 3$ and $\mathrm{C} 7$ side chains yielded better detection efficacy by sandwich immunoassay after binding to PBP2 $x^{*}$, such as CTRX, CFT, CFP, CPZ, and CFM. As shown in Figure 5, the $\mathrm{C} 3$ side chain of cephalosporins protrudes deep into the cavity, whereas the C7 side chain moiety of the hapten is partially exposed to solvent, which indicated the criticality of the $\mathrm{C} 3$ side chain in inducing a conformational change of PBP2 $x^{*}$. Of these, the CTRX exhibited the best detection effect by sandwich immunoassay, which most likely was facilitated by the more complex $\mathrm{C} 3$ and $\mathrm{C} 7$ side chains that formed multiple hydrogen bonds with PBP2x* (Figure S1). In total, the sandwich immunoassay results, together with molecular recognition study, demonstrated that the complexity of the molecular structure of the drug affected the conformational changes of the receptor after binding, which in turn affected the subsequent sandwich detection. Moreover, in the process of screening optimal antibody pairs for establishing the sandwich immunoassay, the sandwich detection could be achieved only when the pAb derived from PBP2 ${ }^{*}-\mathrm{CTX}$ was used as the detection antibody, coupled with $\mathrm{mAb} 4 \mathrm{H} 11$ from PBP2 $x^{*}$-AMP as the capture antibody. In comparison to PNG, AMP, AMX, and $\mathrm{KF}$, the CTX, with a more complex and rigid structure, exhibited the stronger induction ability to induce conformational changes of the receptor, and thereby promoted the generation of anti-metatype antibodies. Therefore, in follow-up association studies, the $\beta$-lactams with a larger size and more complex structures should be selected for binding to the receptor and then used as the immunogen to screen anti-metatype antibodies, and hence achieve broad-spectrum reorganization for $\beta$-lactams using a sandwich immunoassay. 

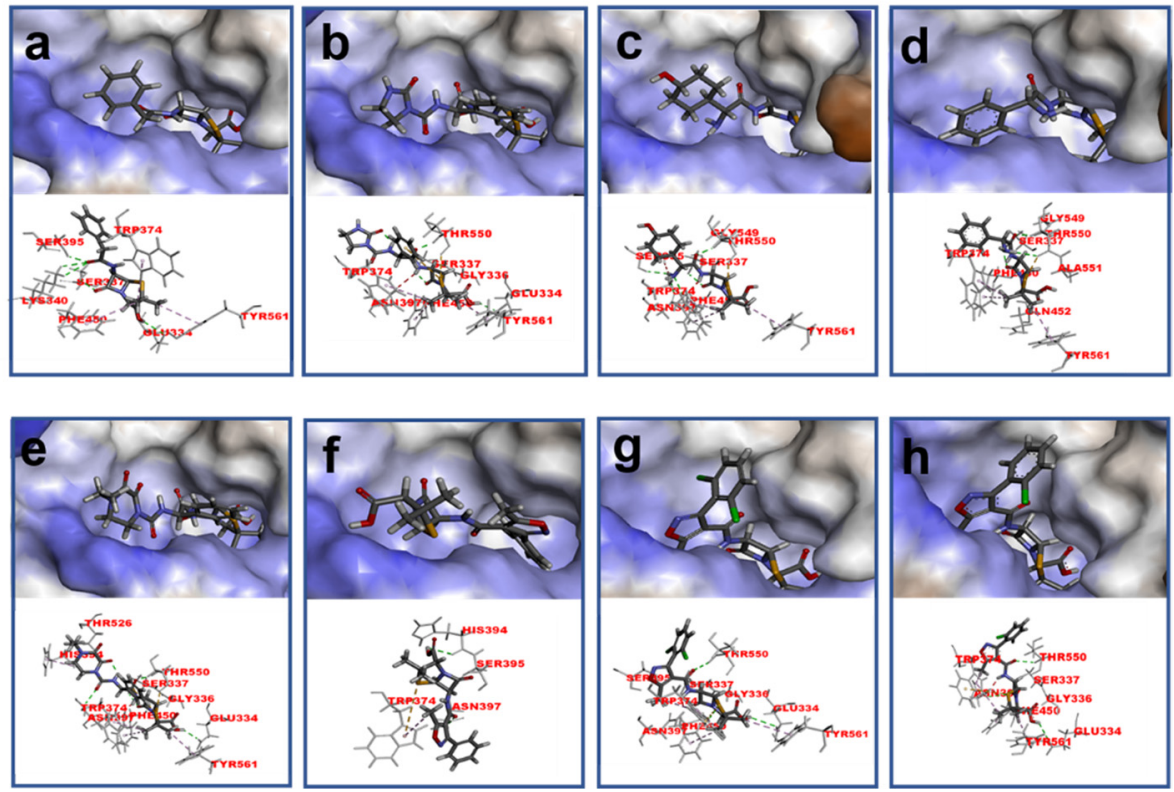

Figure 4. Schematic representation of the interactions between PBP2x* (PDB code: $2 z 2 \mathrm{~m}$ ) and (a) PNG; (b) AZL; (c) AMX; (d) AMP; (e) PIPC; (f) OXA; (g) DCX; and (h) CLX. Hydrogen bonds are shown as green dashed lines, and hydrophobic interactions are displayed as purple dashes.
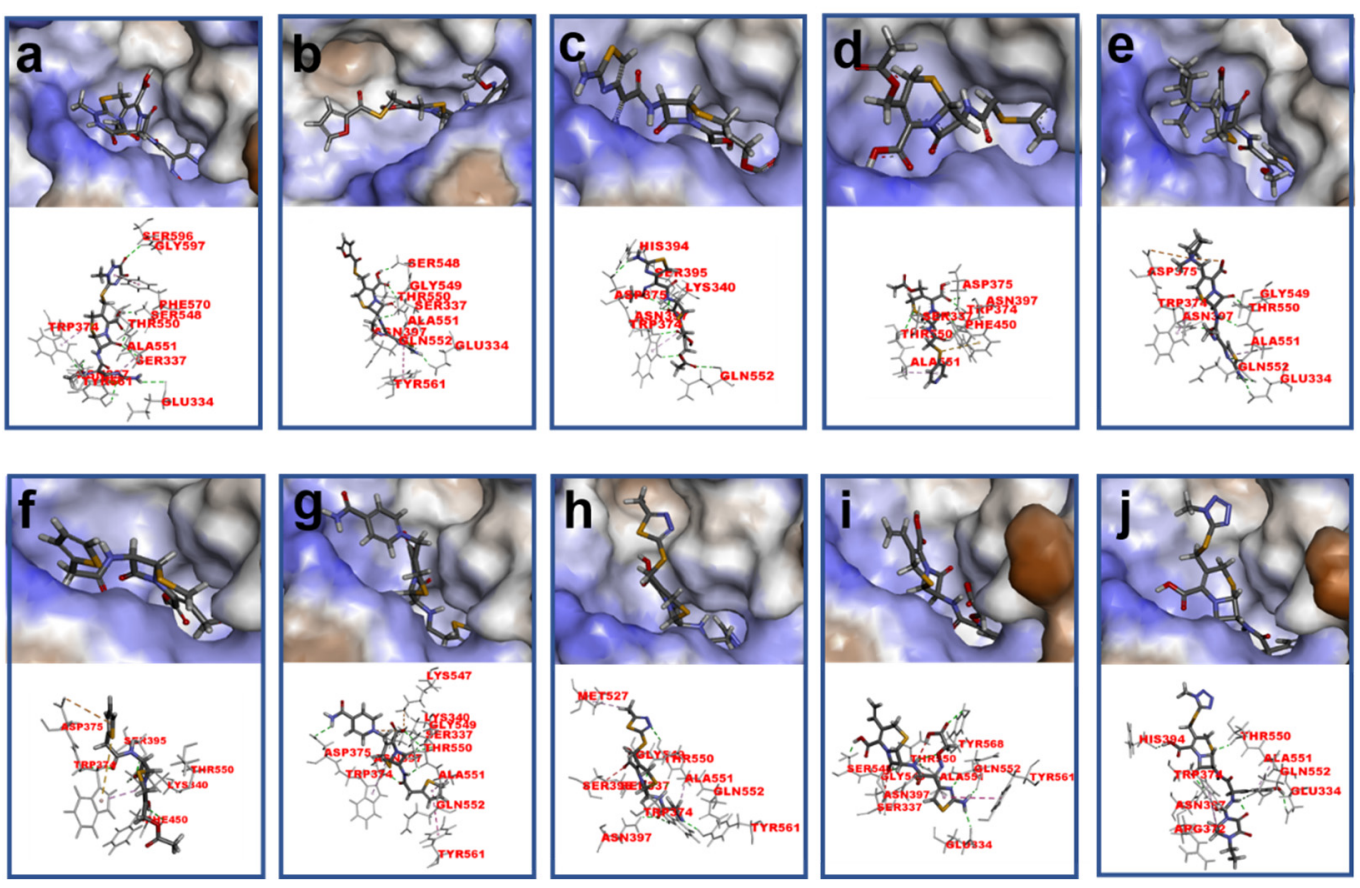

Figure 5. Schematic representation of the interactions between PBP2x* (PDB code: $2 z 2 \mathrm{~m}$ ) and (a) CTRX; (b) CFT; (c) CTX; (d) CFAP; (e) CFP; (f) KF; (g) CFN; (h) CFZ; (i) CFM; and (j) CPZ. Hydrogen bonds are shown as green dashed lines, and hydrophobic interactions are displayed as purple dashes.

\section{Materials and Methods}

\subsection{Materials}

Penicillin G (PNG), ampicillin (AMP), amoxicillin (AMX), azlocillin (AZL), oxacillin (OXA), piperacillin (PIPC), cefalothin (KF), cefazolin (CFZ), ceftiofur (CFT), cefepime (CFP), and cefixime (CFM) were purchased from the National Institutes for Food and Drug Control (Beijing, China). Cloxacillin (CLX), dicloxacillin (DCX), cefoperazone (CPZ) and cefotaxime (CTX) were purchased from Dr. Ehrenstorfer (Augsburg, Germany). Cefalonium (CFN), 
CTRX, cefapirin (CFAP), horseradish peroxidase (HRP), poly (ethylene glycol) (PEG) 1500, hypoxanthine aminopterin thymidine (HAT), incomplete Freund's adjuvant (IFA), and complete Freund's adjuvant (CFA) were purchased from Sigma-Aldrich (St. Louis, MO, USA). Fetal calf serum and Dulbecco's Modified Eagle's Medium (DMEM) were obtained from Gibco BRL (Carlsbad, CA, USA). The 3,3',5,5'-tetramethylbenzidine (TMB) and goat anti-mouse IgG were acquired from Jackson ImmunoResearch (West Grove, PA, USA). The HRP conjugation labeling kit was from Abcam (Toronto, Canada). Reagent grade solvents and salts were supplied by Beijing Chemical Reagent Co. (Beijing, China). The buffer solutions are listed in the Supplementary Materials.

\subsection{Determination of Binding Affinity of PBP2 $x^{*}$ with $18 \beta$-Lactams}

The PBP2 $x^{*}(100 \mu \mathrm{L} /$ well $)$ was diluted to an appropriate concentration and coated on microtiter plates, and incubated overnight at $4{ }^{\circ} \mathrm{C}$. After the solution was poured, the plates were washed 3 times with washing buffer and patted dry. Then, $150 \mu \mathrm{L}$ of blocking solution was added to each well, followed by $1 \mathrm{~h}$ of incubation at $37^{\circ} \mathrm{C}$. The $\beta$-lactam standards $(50 \mu \mathrm{L})$, which were diluted to a series of concentrations, were added into each well, then $50 \mu \mathrm{L}$ of the enzyme marker prepared in our previous study [24] was added, and incubated at $37^{\circ} \mathrm{C}$ for $30 \mathrm{~min}$. After the washing procedure, the color was developed by adding tetramethylbenzidine (TMB) substrate. Finally, $2 \mathrm{M} \mathrm{H}_{2} \mathrm{SO}_{4}(50 \mu \mathrm{L} /$ well) was used to stop the enzymatic reaction, and the optical density (OD) values of $450 \mathrm{~nm}$ was measured.

\subsection{Preparation and Identification of PBP2 $x^{*}$-Drug Complexes}

The purified PBP2 $x^{*}(10.0 \mathrm{mg})$ was dissolved in $5 \mathrm{~mL}$ PBS, followed by adding 10-fold molar excess of $\beta$-lactams (PNG, AMP, AMX, CTX, and KF). The reaction mixture was incubated for $24 \mathrm{~h}$ at $4{ }^{\circ} \mathrm{C}$ and dialyzed against $\mathrm{PBS}$ for 3 days. To ensure that the active sites of the PBP2 $x^{*}$ (receptor) were completely occupied by the $\beta$-lactams (ligand), they were identified by a direct enzyme-linked immunosorbent assay (ELISA). Briefly, the microplates were first coated with the receptor-ligand complex $(100 \mu \mathrm{L} /$ well $)$, which was diluted with $\mathrm{CB}$ buffer and then incubated at $4{ }^{\circ} \mathrm{C}$ overnight. The coating solution was then discarded and washed by washing buffer. Blocking buffer was then added to the plates $(150 \mu \mathrm{L} /$ well $)$ and incubated for $2 \mathrm{~h}$ at $37^{\circ} \mathrm{C}$. After patting to dry, $100 \mu \mathrm{L}$ diluted PNG-HRP, which was prepared in our previous study [24], was then added and incubated for $30 \mathrm{~min}$ at $37^{\circ} \mathrm{C}$. TMB substrate $\left(100 \mu \mathrm{L} /\right.$ well) was added and incubated for $15 \mathrm{~min}$ at $37^{\circ} \mathrm{C}$, and then $2 \mathrm{M}$ $\mathrm{H}_{2} \mathrm{SO}_{4}(50 \mu \mathrm{L} /$ well $)$ was used for reaction stopping, and the OD values at $450 \mathrm{~nm}$ were measured.

\subsection{Preparation of Anti-Metatype Antibody \\ 3.4.1. Rabbit pAbs}

Female New Zealand white rabbits were used to produce pAbs. Five complexes (including PBP2 $x^{*}-\mathrm{PNG}, \mathrm{PBP} 2 x^{*}-\mathrm{AMP}, \mathrm{PBP} 2 x^{*}-\mathrm{AMX}, \mathrm{PBP} 2 x^{*}-\mathrm{CTX}$, and PBP2 $x^{*}-\mathrm{KF}$ ) and individual PBP2 $x^{*}$ were used as immunogens to immunize two rabbits. The immunization procedure was described in our previous studies [29]. The titers of antisera were monitored by non-competitive ELISA. Briefly, the ELISA plates were coated with the corresponding PBP2 $x^{*}$-drug complex $(100 \mu \mathrm{L} /$ well $)$ and incubated at $4{ }^{\circ} \mathrm{C}$ for overnight. After blocking, $100 \mu \mathrm{L}$ of diluted serum samples was added and incubated at $37^{\circ} \mathrm{C}$ for $1 \mathrm{~h}$. The HRPlabeled goat anti-rabbit IgG (100 $\mu \mathrm{L} /$ well $)$ was added after the washing step, and the plates were incubated for $1 \mathrm{~h}$ at $37^{\circ} \mathrm{C}$. Then, plates were washed three times, followed by a color development. The OD values of each well were measured at $450 \mathrm{~nm}$. A positive antibody response was defined as an OD value higher than 2.1 times the mean of OD values of the serum samples from rabbit immunized with PBP2x*. 


\subsubsection{Mouse $\mathrm{mAbs}$}

Five eight-week-old female Balb/c mice were first immunized with $100 \mu \mathrm{g}$ of each immunogen in $0.1 \mathrm{~mL}$ of PBS and $0.1 \mathrm{~mL}$ of CFA. For the second immunization, the mice were boosted with the mixture of immunogen $(100 \mu \mathrm{g})$ and IFA. After the fourth immunization, the mouse with the highest dilution was sacrificed, and the splenocytes were extracted and fused with SP2/0 myeloma cells. The hybridoma cells were screened for antibody production using non-competitive ELISA as described above, followed by subcloning based on the limiting dilution method. The clones with the high inhibition were cloned third, prior to ascites production. The $\mathrm{mAb}$ was purified by saturated ammonium sulfate precipitation from ascites and stored at $-20^{\circ} \mathrm{C}$.

\subsection{Screening for Pairing Antibodies}

Microtiter plates were coated with $100 \mu \mathrm{L}$ anti-mouse IgG antibody in CB buffer and incubated at $4{ }^{\circ} \mathrm{C}$ overnight. The plates were subsequently washed and blocked with $150 \mu \mathrm{L}$ of $2 \%$ skim milk. Then, $100 \mu \mathrm{L}$ of diluted mAb was added to the wells and incubated for $1 \mathrm{~h}$ at $37^{\circ} \mathrm{C}$. After washing, $100 \mu \mathrm{L}$ individual PBP2x* or receptor-ligand complexes of $18 \beta$-lactams with PBP2 $x^{*}$ that were diluted to $1 \mu \mathrm{g} / \mathrm{mL}$ was added. The incubation was carried out at $37^{\circ} \mathrm{C}$ for $1 \mathrm{~h}$, followed by another washing procedure. Then, $100 \mu \mathrm{L}$ diluted HRP-labeled pAb was added to the wells and incubated for $1 \mathrm{~h}$ at $37^{\circ} \mathrm{C}$. The TMB substrate solution was added after washing, followed by the addition of $2 \mathrm{M} \mathrm{H}_{2} \mathrm{SO}_{4}$ to stop the reaction, and finally the OD values were measured at $450 \mathrm{~nm}$.

\section{Sandwich Immunoassay for CTRX}

Microtiter plates were coated with anti-mouse IgG antibody first, and then the $\mathrm{mAb}$ diluted to the appropriate concentration was added and incubated at $37^{\circ} \mathrm{C}$ for $1 \mathrm{~h}$. At the same time, appropriately diluted PBP2 $\mathrm{x}^{*}$ was incubated with different concentrations of $\operatorname{CTRX}(0.1,1,10,100$, or $1000 \mathrm{ng} / \mathrm{mL})$ at $37^{\circ} \mathrm{C}$ for $1 \mathrm{~h}$. Then, the wells coated with $\mathrm{mAb}$ were washed, and the prepared PBP $2 x^{*}$-drug complexes were added. The incubation was carried out at $37^{\circ} \mathrm{C}$ for $1 \mathrm{~h}$, followed by the addition of HRP-labeled pAb. After $1 \mathrm{~h}$ of incubation, the color was developed by adding $100 \mu \mathrm{L}$ of the TMB substrate solution. The solution was incubated for $15 \mathrm{~min}$ at $37^{\circ} \mathrm{C}$ before the enzymatic reaction was stopped by adding $50 \mu \mathrm{L}$ of $2 \mathrm{M} \mathrm{H}_{2} \mathrm{SO}_{4}$. The OD values of each well was measured at $450 \mathrm{~nm}$.

\subsection{Extraction of Molecular Descriptors}

Three-dimensional (3D) structures of $\beta$-lactam molecules were built in GaussView 5.0 software (Gaussian, Wallingford, CT, USA). Then, all molecules were optimized by density functional theory (DFT) calculations at the TVZP functional level with an M06-2X basis set using the Gaussian 09 software (Gaussian, Wallingford, CT, USA) $[28,30]$. The descriptors of $\beta$-lactams, including the energy (E) and dipole moment $(\mu)$, were extracted from the Guassian output file. The hydrophobic constant (Log P) was obtained using ChemDraw (PerkinElmer, Waltham, MA, USA). The polar surface area (PSA), molecule volume (Vm), molecular polarity index (MPI), and surface area (SA) were extracted using Multiwfn 3.7 (dev) code [31].

\subsection{Molecular Docking between the $\beta$-Lactams and PBP2x*}

The bindings between $18 \beta$-lactams and the PBP2 $x^{*}$ (PDB code: $2 \mathrm{z} 2 \mathrm{~m}$ ) were performed by CDOCKER (Discovery Studio 17.1, Dassault Systèmes, BIOVIA Corp., San Diego, CA, USA). After docking ligands into the top-ranked cavity of the antibody, the best binding pose with the highest score for each ligand was selected.

\section{Conclusions}

In the current study, we presented the first attempt to prepare anti-metatype antibodies for the complex formed by PBP $2 x^{*}$ and $\beta$-lactams, and developed a sandwich immunoassay for $\beta$-lactam detection. It was found that the affinity between PBP2 $x^{*}$ and $\beta$-lactams did not 
seem to be a key factor in the capacity of antibody screening and sandwich immunoassay development, but was closely related to the size and complexity of the molecular structure of drugs. Therefore, in the follow-up study, the complex of PBP $2 x^{*}$ and $\beta$-lactams with a relatively complex molecular structure should be selected as the immunogen to obtain paired antibodies that can be used for sandwich detection, which is expected to significantly improve the detection performance. This study will provide practical experience and a theoretical basis for subsequent screening of more broad-spectrum and sensitive antibodies against $\beta$-lactams.

Supplementary Materials: The following are available online, Figure S1: Two-dimensional schematic diagram of the interactions between PBP2x (PDB code: 2z2m) and (A) PNG; (B) AZL; (C) AMX; (D) AMP; (E) PIPC; (F) OXA; (G) DCX; (H) CLX; (I) CTRX; (J) CFT; (K) CTX; (L) CFAP; (M) CFP; (N) $\mathrm{KF}$; (O) CFN; (P) CFZ; (Q) CFM; and (R) CPZ. Hydrogen bonds are shown as green dashed lines, hydrophobic interactions are displayed as purple dashes, and the electrostatic force is expressed as orange dashes. Table S1: Identification of PBP2x*-drugs. Table S2: Molecular descriptors of $\beta$-lactams.

Author Contributions: Conceptualization, writing—original draft preparation, Y.B.; methodology, L.D. and W.W.; software, Z.L. and J.K.; validation, J.S.; investigation, Z.W.; resources, writing-review and editing, K.W. All authors have read and agreed to the published version of the manuscript.

Funding: This work was supported by the National Key Research and Development Program (2018YFC1602900) and Sanming Project of Medicine in Shenzhen (SZSM201611068).

Institutional Review Board Statement: The laboratory animals (rabbits and mice) in our experiments were used in accordance with the relevant Chinese laws and according to the China Agriculture University regulations concerning protection of animals used for scientific purposes (2010-SYXK0037). The use of mice in this study was approved by the Ethics Committee on Experimental Animals and Animal Tests of China Agricultural University under review number AW01067102-2.

Conflicts of Interest: The authors declare no conflict of interest.

Sample Availability: Samples of the compounds are available from the authors.

\section{References}

1. Self, C.H.; Cook, D.B. Advances in immunoassay technology. Curr. Opin. Biotechnol. 1996, 7, 60-65. [CrossRef]

2. Lawler, K.; Kijanka, G. Clinical applications of immunoassays. In Applications and Future Trends; Immunoassays, D., Ed.; Pan Stanford: New York, NY, USA, 2017; pp. 161-190.

3. Yalow, R.S.; Berson, S.A. Assay of plasma insulin in human subjects by immunological methods. Nature 1959, 184, 1648-1649. [CrossRef] [PubMed]

4. Kobayashi, N.; Goto, J. Noncompetitive immunoassays for small molecules with high sensitivity and specificity. Adv. Clin. Chem. 2001, 36, 139-170.

5. Fan, M.; He, J. Recent progress in noncompetitive hapten immunoassays: A review. In Trends in Immunolabelled and Related Techniques; Intech: Rijeka, Croatia, 2012; pp. 53-66.

6. Barnard, G.; Kohen, F. Idiometric assay: Noncompetitive immunoassay for small molecules typified by the measurement of estradiol in serum. Clin. Chem. 1990, 36, 1945-1950. [CrossRef] [PubMed]

7. Ullman, E.F.; Milburn, G.; Jelesko, J.; Radika, K.; Pirio, M.; Kempe, T.; Skold, C. Anti-immune complex antibodies enhance affinity and specificity of primary antibodies. Proc. Natl. Acad. Sci. USA 1993, 90, 1184-1189. [CrossRef]

8. Akter, S.; Vehniäinen, M.; Spoof, L.; Nybom, S.; Meriluoto, J.; Lamminmäki, U. Broad-spectrum noncompetitive immunocomplex immunoassay for cyanobacterial peptide hepatotoxins (microcystins and nodularins). Anal. Chem. 2016, 88, 10080-10087. [CrossRef] [PubMed]

9. Arola, H.; Tullila, A.; Kiljunen, H.; Campbell, K.; Siitari, H.; Nevanen, T. Specific noncompetitive immunoassay for HT-2 mycotoxin detection. Anal. Chem. 2016, 88, 2446-2452. [CrossRef] [PubMed]

10. Ueda, H.; Yokozeki, T.; Arai, R.; Tsumoto, K.; Kumagai, I.; Nagamune, T. An optimized homogeneous noncompetitive immunoassay based on the antigen-driven enzymatic complementation. J. Immunol. Methods 2003, 279, 209-218. [CrossRef]

11. Zhang, J.; Wang, Z.; Wen, K.; Liang, X.; Shen, J. Penicillin-binding protein 3 of streptococcus pneumoniae and its application in screening of $\beta$-lactams in milk. Anal. Biochem. 2013, 442, 158-165. [CrossRef]

12. Pitts, C.R.; Lectka, T. Chemical synthesis of beta-lactams: Asymmetric catalysis and other recent advances. Chem. Rev. 2014, 114, 7930-7953. [CrossRef]

13. European Communities. Commission Regulation (EU) No. 37/2010. Off. J. Eur. Communities 2009, OJL 15, 1-72. 
14. Boison, J.O.; Lee, S.; Matus, J. A multi-residue method for the determination of seven polypeptide drug residues in chicken muscle tissues by LC-MS/MS. Anal. Bioanal. Chem. 2015, 407, 4065-4078. [CrossRef]

15. Hoff, R.B.; Pizzolato, T.M.; Peralba, M.C.R.; Díaz-Cruz, M.S.; Barceló, D. Determi-nation of sulfonamide antibiotics and metabolites in liver, muscle and kidney samples by pressurized liquid extraction or ultrasound-assisted extraction followed by liquid chromatography-quadrupole linear ion trap-tandem mass spectrometry (HPLC-QqLIT-MS/MS). Talanta 2015, 134, 768-778.

16. Stead, S.L.; Ashwin, H.; Richmond, S.F.; Sharman, M.; Langeveld, P.C.; Barendse, J.P.; Stark, J.; Keely, B.J. Evaluation and validation according to international standards of the Delvotest ${ }^{\circledR}$ SP-NT screening assay for antimicrobial drugs in milk. Int. Dairy J. 2008, 18, 3-11. [CrossRef]

17. Strasser, A.; Usleber, E.; Schneider, E.; Dietrich, R.; Burk, C.; Martlbauer, E. Improved enzyme immunoassay for group-specific determination of penicillins in milk. Food Agric. Immunol. 2003, 15, 135-143. [CrossRef]

18. Gustavsson, E.; Bjurling, P.; Degelaen, J.; Sternesjö, Å. Analysis of $\beta$-lactam antibiotics using a microbial receptor protein-based biosensor assay. Food Agric. Immunol. 2002, 14, 121-131. [CrossRef]

19. Li, W.; Liu, C.; Zhang, H.; Ye, K.; Zhang, G.; Zhang, W.; Duan, Z.; You, S.; Lei, A. Palladium-catalyzed oxidative carbonylation of N-Allylamines for the synthesis of beta-lactams. Angew. Chem. Int. Ed. 2014, 53, 2443-2446. [CrossRef]

20. Burmester, J.; Spinelli, S.; Pugliese, L.; Krebber, A.; Honegger, A.; Jung, S.; Schimmele, B.; Cambillau, C.; Plückthun, A. Selection, Characterization and X-ray structure of anti-ampicillin single-chain Fv fragments from phage-displayed murine Antibody libraries. J. Mol. Biol. 2001, 309, 671-685. [CrossRef]

21. Ahmed, S.; Ning, J.; Cheng, G.; Ahmad, I.; Li, J.; Mingyue, L.; Qu, W.; Iqbal, M.; Shabbir, M.A.; Yuan, Z. Receptor-based screening assays for the detection of antibiotics residues-A review. Talanta 2017, 166, 176-186. [CrossRef]

22. Chen, Y.; Wang, Y.; Liu, L.; Wu, X.; Xu, L.; Kuang, H.; Li, A.; Xu, C. A gold immunochro-matographic assay for the rapid and simultaneous detection of fifteen $\beta$-lactams. Nanoscale 2015, 7, 16381-16388. [CrossRef] [PubMed]

23. Cacciatore, G.; Petz, M.; Rachid, S.; Hakenbeck, R.; Bergwerff, A. Development of an optical biosensor assay for detection of $\beta$-lactam antibiotics in milk using the penicillin-binding protein $2 x^{*}$. Anal. Chim. Acta 2004, 520, 105-115. [CrossRef]

24. Zeng, K.; Zhang, J.; Wang, Y.; Wang, Z.H.; Zhang, S.; Wu, C.; Shen, J. Development of a rapid multi-residue assay for detecting beta-lactams using penicillin binding protein $2 x^{*}$. Biomed. Environ. Sci. BES 2013, 26, 100-109. [PubMed]

25. Yamada, M.; Watanabe, T.; Baba, N.; Takeuchi, Y.; Ohsawa, F.; Gomi, S. Crystal structures of biapenem and tebipenem complexed with penicillin-binding proteins 2X and 1A from Streptococcus pneumoniae. Antimicrob. Agents Chemother. 2008, 52, $2053-2060$. [CrossRef]

26. Yamada, M.; Watanabe, T.; Miyara, T.; Baba, N.; Saito, J.; Takeuchi, Y.; Ohsawa, F. Crystal structure of cefditoren complexed with Streptococcus pneumoniae penicillin-binding protein $2 X$ : Structural basis for its high antimicrobial activity. Antimicrob. Agents Chemother. 2007, 51, 3902-3907. [CrossRef] [PubMed]

27. Li, C.; Liang, X.; Wen, K.; Li, Y.; Zhang, X.; Ma, M.; Yu, X.; Yu, W.; Shen, J.; Wang, Z. Class-specific monoclonal antibodies and dihydropteroate synthase in bioassays used for the detection of sulfonamides: Structural insights into recognition diversity. Anal. Chem. 2019, 91, 2392-2400. [CrossRef] [PubMed]

28. Zhao, Y.; Truhlar, D.G. The M06 suite of density functionals for main group thermochemistry, thermochemical kinetics, noncovalent interactions, excited states, and transition elements: Two new functionals and systematic testing of four M06-class functionals and 12 other functionals. Theor. Chem. Acc. 2008, 120, 215-241.

29. Weigend, F.; Ahlrichs, R. Balanced basis sets of split valence, triple zeta valence and quadruple zeta valence quality for $H$ to $R n$ : Design and assessment of accuracy. Phys. Chem. Chem. Phys. 2005, 7, 3297-3305. [CrossRef] [PubMed]

30. Wang, Z.; Zhang, H.; Ni, H.; Zhang, S.; Shen, J. Development of a highly sensitive and specific immunoassay for enrofloxacin based on heterologous coating haptens. Anal. Chim. Acta 2014, 820, 152-158. [CrossRef]

31. Lu, T.; Chen, F. Multiwfn: A multifunctional wavefunction analyzer. J. Comput. Chem. 2012, 33, 580-592. [CrossRef] 